\title{
Helicobacter pylori induces mono-(adenosine 5'-diphosphate)- ribosylation in human gastric adenocarcinoma
}

\author{
TAKASHI AKAI ${ }^{1,2}$, YOSHIHIRO NABEYA ${ }^{1}$, KINNOSUKE YAHIRO ${ }^{2}$, NAOKO MORINAGA $^{2}$, \\ KANAE MITSUHASHI ${ }^{2,3}$, MASAHITO INOUE ${ }^{1,2}$, AKIO SAKAMOTO ${ }^{4}$, \\ TAKENORI OCHIAI $^{1}$ and MASATOSHI NODA ${ }^{2}$
}

\begin{abstract}
Departments of ${ }^{1}$ Frontier Surgery, ${ }^{2}$ Molecular Infectiology, and ${ }^{3}$ Medical and Clinical Oncology, Chiba University Graduate School of Medicine, 1-8-1 Inohana, Chuo-ku, Chiba 260-8670; ${ }^{4}$ Department of Surgery, Narutou General Hospital, 167 Narutou, Narutou-machi, Sanbu-gun, Chiba 289-1326, Japan
\end{abstract}

Received March 23, 2006; Accepted May 30, 2006

\begin{abstract}
Mono-(adenosine 5'-diphosphate) (ADP)-ribosylation, which transfers an ADP-ribose from nicotinamide adenine dinucleotide (NAD) to an acceptor protein, is an important post-translational modification of cellular proteins. Several bacterial toxins are known to possess the mono-ADPribosyltransferase activity to catalyze this reaction as a possible pathogenic factor. Therefore, the aim of this study was to examine whether $H$. pylori may also induce mono-ADPribosylation in a human gastric mucosal protein in association with gastric cancer development. Tumorous and adjacent non-tumorous mucosal tissue specimens were obtained from the surgically removed stomachs of 5 patients with gastric adenocarcinoma, and then were homogenized into cytosolic and membranous fractions. Each homogenate or an $H$. pylori extract was assayed for mono-ADP-ribosylation with [adenylate- ${ }^{32} \mathrm{P}$ ]-NAD and 3-aminobenzamide, a potent inhibitor of poly-ADP-ribosylation. The radiolabeled proteins were separated by sodium dodecylsulfate-polyacrylamide gel electrophoresis followed by radio-image analysis. In the extracts from $H$. pylori, a strain-dependent, endogenous radio-
\end{abstract}

Correspondence to: Dr Yoshihiro Nabeya, Department of Frontier Surgery (M9), Chiba University Graduate School of Medicine, 1-8-1 Inohana, Chuo-ku, Chiba 260-8670, Japan

E-mail: nabeya-y@faculty.chiba-u.jp

Abbreviations: H. pylori, Helicobacter pylori; VacA, vacuolating cytotoxin; cagA, cytotoxin-associated gene A; CagA, cagA product; ADP, adenosine 5'-diphosphate; NAD, nicotinamide adenine dinucleotide; FBS, fetal bovine serum; SDS, sodium dodecylsulfate; DTT, dithiothreitol; SDS-PAGE, SDS-polyacrylamide gel electrophoresis; PVDF, poly-(vinylidene difluoride); PEI, polyethylenimine; AMP, adenosine 5'-monophosphate; Rho, Ras homologous

Key words: Helicobacter pylori, gastric carcinoma, mono-(adenosine 5'-diphosphate)-ribosylation, mono-(adenosine 5'-diphosphate)ribosyltransferase labeling of $70-\mathrm{kDa}$ protein was detected. An assay of the membranous fractions from 5 gastric adenocarcinomas with the extract of $\mathrm{OMH} 4$, a clinical H. pylori isolate, revealed notable radiolabelings of 55- and 45-kDa proteins, which were not found without the OMH4 extract. In contrast, the radiolabelings were minimal in the membranous fractions from respective non-tumorous mucosae, and they were not detected in any of the examined cytosolic fractions. All three radiolabelings of 70-, 55-, and 45-kDa proteins were dependent on NAD, but not on ADP-ribose. Snake venom phosphodiesterase digestion of the 3 radiolabeled proteins released only AMP. We thus found that $H$. pylori had an enzymatic mono-ADP-ribosyltransferase activity which enabled it to modify the 55- and $45-\mathrm{kDa}$ membranous proteins of human gastric adenocarcinoma, as well as the 70-kDa protein of $H$. pylori itself. The possible roles underlying our observations on carcinogenesis or development of human gastric carcinoma are yet to be elucidated.

\section{Introduction}

Helicobacter pylori (H. pylori) is a spiral-shaped, gramnegative bacteria, which was first isolated from the stomachs of patients with gastritis, and subsequently from those of peptic ulcer patients (1). This pathogenic bacterium is unique in its ability to colonize the human gastric mucosa and persistently infects more than half of all people worldwide, while the prevalence of its infection is known to increase significantly with advanced age (2). Consistent $H$. pylori infection has been reported to result in gastric inflammation and to increase the risk of gastric adenocarcinoma or lymphoma as well as peptic ulcer disease (2-5). The World Health Organization defines $H$. pylori as a class 1 'definite carcinogen' (6).

H. pylori has been suggested to possess many virulent pathogenic factors such as urease, adhesins, protease, lipase, vacuolating cytotoxin ( $\mathrm{VacA})$, and cytotoxin-associated gene A (cagA) product (CagA) (5,7-9). Recent experimental studies have revealed that VacA behaves as a ligand for protein tyrosine phosphatase receptor type $\mathrm{Z}$ and its erroneous signaling induces gastric ulcers $(10,11)$. However, little is yet known 
regarding how $H$. pylori might be biologically associated with carcinogenesis or development of gastric carcinoma, while the epidemiologic relationship between $H$. pylori infection and gastric adenocarcinoma has been reported (2-6).

Adenosine 5'-diphosphate (ADP)-ribosylation is one of the important post-translational modifications of cellular proteins in which the ADP-ribose moiety of nicotinamide adenine dinucleotides (NAD) is transferred enzymatically to specific amino acid residues in target proteins. The modifications are categorized into two classes of reactions, i.e., poly-ADP-ribosylation and mono-ADP-ribosylation $(12,13)$. Poly-ADP-ribosylation is catalyzed by an enzyme, poly-(ADP-ribose) polymerase, which implicates a nuclear protein involved in DNA repair, cell differentiation and the maintenance of chromatin structure (14). Recently, polyADP-ribosylation and the expression of poly-(ADP-ribose) polymerase have been reported to significantly increase in human hepatocellular carcinoma, suggesting that the enhancement of poly-ADP-ribosylation in tumors compared with normal liver tissues might play a role in the growth of hepatocellular carcinoma (15). In contrast, mono-ADP-ribosylation is catalyzed by mono-ADP-ribosyltransferase, and this enzyme transfers only one moiety of ADP-ribose to an acceptor protein $(13,16-22)$. Mono-ADP-ribosylation was initially documented for several bacterial toxins, such as pertussis toxin, cholera toxin, diphtheria toxin, and botulinum toxin, which have been shown to possess the mono-ADP-ribosyltransferase activity, and these toxins act as a pathogenic factor by modifying human crucial proteins, thus resulting in the activation or inactivation of cell functions (16-18). Moreover, several other bacteria have also been suggested to possibly possess this transferase activity (18-20). Therefore, an alteration in the level of mono-ADP-ribosylation of human gastric mucosal protein by $H$. pylori infection is of interest, from the viewpoint of possible pathogenic factors for gastric adenocarcinoma, but it has not yet been explored.

The aim of this study was thus to examine whether $H$. pylori possesses mono-ADP-ribosyltransferase activity, particularly for modifying some protein in the human gastric mucosa. We herein demonstrate, for the first time, the presence of endogenous mono-ADP-ribosylation of $70-\mathrm{kDa}$ protein in the extract of clinically isolated $H$. pylori. Furthermore, $H$. pylori extract has also been shown to cause exogenous monoADP-ribosylation of membranous proteins of human gastric adenocarcinoma in vitro. Our data suggest that the monoADP-ribosyltransferase activity derived from $H$. pylori may be related to the carcinogenesis or development of gastric carcinoma, though a possible underlying biological mechanism associated with some type of pathogenicity has yet to be elucidated.

\section{Materials and methods}

Bacterial culture and preparation of extract from $H$. pylori. H. pylori strains of ATCC43504 and ATCC49503 were obtained from American Type Culture Collection (Manassas, VA, USA). H. pylori OMH4, by courtesy of Dr T. Fujioka (Oita University Faculty of Medicine, Oita, Japan), was obtained from a Japanese patient with gastric ulcer. All strains were cultivated in Brain Heart Infusion broth (Becton Dickinson,
Sparks, MD, USA) containing 10\% fetal bovine serum (FBS) (Intergen, Purchase, NY, USA), and 15\% (v/v) glycerol (Wako Pure Chemical Industries, Osaka, Japan), and they were stored at $-80^{\circ} \mathrm{C}$. The bacteria were cultured in a controlled microaerophilic atomosphere of $10 \% \mathrm{O}_{2}$ and $10 \% \mathrm{CO}_{2}$ with AneroPack Helico (Mitsubishi Gas Chemical Co., Inc., Tokyo, Japan). A portion of the stock culture was inoculated into Brain Heart Infusion agar (Becton Dickinson) supplemented with $10 \% \mathrm{FBS}$ and incubated at $37^{\circ} \mathrm{C}$ for 3 days. The bacteria were harvested and then inoculated into $100 \mathrm{ml}$ of Brain Heart Infusion broth with 10\% FBS and incubated for a further 3 days. H. pylori cells were centrifuged at 13,500 x g for $20 \mathrm{~min}$, and the pellet was suspended in $10 \mathrm{ml}$ of $10 \mathrm{mM}$ Tris- $\mathrm{HCl}$ ( $\mathrm{pH} 7.5$ ). The suspension was shaken upside-down for $20 \mathrm{~min}$ at $4^{\circ} \mathrm{C}$, and the residue of bacterial cells was removed by centrifugation at $13,500 \mathrm{x} \mathrm{g}$ for $20 \mathrm{~min}$. The supernatant was sterilized by filtration $(0.45-\mu \mathrm{m}$ pore-size filters); the filtrate was divided and stored at $-80^{\circ} \mathrm{C}$ until its use as the H.pylori extract.

Preparation of homogenates from human stomachs. Specimens were taken from human gastric adenocarcinoma and adjacent non-tumorous mucosae in surgically removed stomachs of 5 patients with histologically proven gastric adenocarcinoma in the antrum or corpus, all of whom underwent subtotal distal gastrectomy (Table I). Of the 5 patients, four patients were male, and 4 patients had diffuse-type gastric cancer according to the classification of Lauren (23). In all 5 patients, the status of $H$. pylori infection was determined to be positive by the ${ }^{13} \mathrm{C}$-urea breath test (24) before surgery. In accordance with the Declaration of Helsinki, informed consent was obtained from all subjects before they entered this study. Patient recruitment and sample collection were performed according to the guidelines of the protocol approved by the institutional review boards.

The specimens obtained during surgery were homogenized respectively by microhomogenizer with $300 \mu \mathrm{l}$ of the homogenizing buffer containing $20 \mathrm{mM}$ Tris- $\mathrm{HCl}$ (pH 7.5), $150 \mathrm{mM}$ NaCl, 2 mM EDTA, 2 mM EGTA, 4 mM ß-mercaptoethanol, $100 \mu \mathrm{M}$ phenylmethlsulfonyl fluoride, $10 \mu \mathrm{g} / \mathrm{ml}$ aprotinin, and $10 \mu \mathrm{g} / \mathrm{ml}$ leupeptin. After centrifugation at $17,400 \mathrm{x} \mathrm{g}$ for $10 \mathrm{~min}$, the supernatant was stored as a cytosolic fraction at $-80^{\circ} \mathrm{C}$ until use. The resultant pellet was resuspended in the surfactant buffer containing $50 \mathrm{mM}$ Tris- $\mathrm{HCl}(\mathrm{pH} 7.5), 100$ $\mathrm{mM} \mathrm{NaCl}, 5 \mu \mathrm{g} / \mathrm{ml}$ leupeptin, $1 \%$ Triton $\mathrm{X}-100$, and $10 \%$ glycerol. After incubation at $4{ }^{\circ} \mathrm{C}$ for 10 min followed by centrifugation at $17,400 \mathrm{x} \mathrm{g}$ for $10 \mathrm{~min}$, the supernatant was stored as a membranous fraction at $-80^{\circ} \mathrm{C}$ until use.

Mono-ADP-ribosylation assay. Mono-ADP-ribosylation was assayed as described previously $(15,21,22)$ with some modifications. Briefly, the reaction mixture in a final volume of $200 \mu 1$ contained $100 \mathrm{mM}$ Tris- $\mathrm{HCl}$ (pH 7.5), $1 \mathrm{mM}$ EDTA, $10 \mathrm{mM} \mathrm{MgCl} 2,100 \mu \mathrm{M}$ GTP, $5 \mathrm{mM}$ dithiothreitol (DTT), $5 \mu \mathrm{Ci}$ [anenylate- ${ }^{32} \mathrm{P}$ ]-NAD, $3 \mathrm{mM} 3$-aminobenzamide (to suppress poly-ADP-ribosylation) $(25,26)$, and samples (30 $\mu \mathrm{g}$ of the H. pylori extract or/and $30 \mu \mathrm{g}$ protein of cytosolic or membranous fractions from human stomach homogenates). When indicated, excess cold NAD $(\leq 100 \mu \mathrm{M})$ or ADP-ribose $(\leq 1 \mathrm{mM})$ was added to the assay to exclude non-enzymatic 
Table I. Characteristics of 5 patients with gastric cancer.

\begin{tabular}{lcllc}
\hline No. & $\begin{array}{c}\text { Age } \\
\text { (years) }\end{array}$ & Gender & $\begin{array}{c}\text { Histological } \\
\text { type }^{\mathrm{a}}\end{array}$ & $\begin{array}{c}\text { H.pylori } \\
\text { infection }^{\mathrm{b}}\end{array}$ \\
\hline 1 & 82 & Male & Diffuse & + \\
2 & 69 & Male & Diffuse & + \\
3 & 55 & Male & Diffuse & + \\
4 & 68 & Male & Intestinal & + \\
5 & 51 & Female & Diffuse & + \\
\hline
\end{tabular}

${ }^{a}$ According to Lauren's classification (23). ${ }^{b}$ Determined by ${ }^{13} \mathrm{C}$-urea breath test (24) before gastrectomy.

ADP-ribosylation previously reported $(20,27)$. The results of preliminary time-course experiments showed that the radiolabelings observed were time-dependent up to 5-20 min of incubation and then leveled off before rapidly decreasing thereafter. Based on this finding, the incubation period for the remaining experiments was set at $15 \mathrm{~min}$. After incubation at $37^{\circ} \mathrm{C}$ for $15 \mathrm{~min}$, the reaction was terminated by adding $800 \mu 1$ of ice-cold $10 \%$ (wt/vol) trichloroacetic acid. After incubation at $4^{\circ} \mathrm{C}$ for $15 \mathrm{~min}$ and centrifugation at $17,400 \mathrm{x} \mathrm{g}$ for $10 \mathrm{~min}$, the precipitates were washed with acetone, and dissolved in sodium dodecylsulfate (SDS)-sample buffer by boiling for $5 \mathrm{~min}$. Afterwards, the proteins were separated by $8 \%$ SDS-polyacrylamide gel electrophoresis (SDS-PAGE) according to the method of Laemmli (28). The gels were autoradiographed and were evaluated by using a Bio-Image Analyzer (Fujix BAS 2000; Fuji Photo Film Co., Tokyo, Japan), as described previously $(15,22)$.

Snake venom phosphodiesterase digestion. After SDS-PAGE, proteins of the membranous fractions from gastric cancer were transferred to a poly-(vinylidene difluoride) (PVDF) membrane, and then were subjected to autoradiography. Next, small pieces of the membrane that carried radioactive protein were cut, and these pieces were incubated with 2 units of snake venom phosphodiesterase at $37^{\circ} \mathrm{C}$ for $3 \mathrm{~h}$. The digestion products were chromatographed on thin layer polyethylenimine (PEI)-cellulose F plates in $0.9 \mathrm{M}$ acetic acid/0.3 M LiCl, and the separated radioactive material on the plate was identified by its migration relative to the UV light-absorbing standards [NAD, adenosine 5'-monophosphate (AMP), and ADP-ribose] $(19,29)$.

Chemical stability of the ADP-ribose-protein bond. To identify the mono-ADP-ribosylated amino acid residue of the protein, the sensitivity of ADP-ribose linkage to different chemicals was assessed as described previously $(20,29,30)$. The monoADP-ribosylated proteins were separated by SDS-PAGE and transferred to a PVDF membrane. Thereafter, the membrane was incubated with $0.5 \mathrm{M} \mathrm{NaCl}, 50 \%$ formic acid, $25 \mathrm{mM}$ $\mathrm{HgCl}_{2}$, or $0.5 \mathrm{M} \mathrm{NH}_{2} \mathrm{OH}\left(\mathrm{pH} 7.5\right.$ ) at $37^{\circ} \mathrm{C}$ for $3 \mathrm{~h}$. The membranes were subjected to autoradiography for the second time as described above, and then the ADP-ribosylated amino acid residue was assessed.
Immunoprecipitation assay. Thirty micrograms of cytosolic or membranous fraction was mixed with $1 \mu \mathrm{l}$ of anti-Gi $\alpha$ or anti-Gs $\alpha$ antibody, and anti-p53 antibody (1:1000) in a total volume of $200 \mu \mathrm{l}$ of homogenizing buffer, and the mixture was then incubated at $4{ }^{\circ} \mathrm{C}$ overnight. Protein A Sepharose CL-4B beads ( $25 \mu \mathrm{l}$ of $50 \%$ suspension) were subsequently added, and incubation was continued by shaking upsidedown at $4^{\circ} \mathrm{C}$ for another $1 \mathrm{~h}$. The mixture was centrifuged at $17,400 \mathrm{x} g$ for $1 \mathrm{~min}$. The supernatant was recovered, and the residual immunoprecipitates were washed three times with the homogenizing buffer. Both the supernatant and immunoprecipitates were subjected to an ADP-ribosylation assay in the presence of $H$. pylori extract, and the proteins were analyzed first by SDS-PAGE and then subsequently by autoradiography, as described above.

Other methods and chemicals. The protein concentrations were determined using the Bio-Rad protein assay dye reagent kit (Bio-Rad Laboratories, Hercules, CA, USA) and using bovine serum albumin as the standard. [Adenylate- ${ }^{32} \mathrm{P}$ ]-NAD $(5 \mathrm{mCi} / \mathrm{ml}, 800 \mathrm{Ci} / \mathrm{mmol})$ was obtained from DuPont NEN Research Products (Boston, MA, USA), and the snake venom phosphodiesterase was purchased from Worthington Biochemical Co. (Freehold, NJ, USA). The anti-Gi $\alpha$ and anti-Gs $\alpha$ antibodies were obtained from Sigma Chemical Co. (St. Louis, MO, USA), and the anti-p53 antibody (monoclonal DO-1, Ab-6) was purchased from Wako Pure Chemical Industries, Ltd. The PVDF membranes and PEI-cellulose F plates were purchased from Bio-Rad Laboratories and Merck KGaA (Darmstadt, Germany), respectively. Protein A Sepharose CL-4B beads were purchased from Amersham Biosciences Corp. (Piscataway, NJ, USA). All other chemicals used were of the highest standard grade commercially available.

\section{Results}

Protein (70-kDa) acquires endogenous radiolabeling in $H$. pylori extract. When the $H$. pylori extract alone was assayed for mono-ADP-ribosylation under the conditions described in the Materials and methods, the endogenous incorporation of radioactivity into approximately $70-\mathrm{kDa}$ protein of $H$. pylori itself was observed remarkably in $\mathrm{OMH} 4$, a clinical isolate, and weakly in ATCC49503, while no incorporated radiolabelling was found in ATCC43504 (Fig. 1). The degree of radiolabeling of $70-\mathrm{kDa}$ protein depends on the type of $H$. pylori strain. As a result, the extract from $\mathrm{OMH} 4$, which showed the greatest radiolabeling of $70-\mathrm{kDa}$ protein, was selected for further investigation in this study.

H. pylori (OMH4) extract induces radiolabelings of 55and 45-kDa proteins in the membranous fraction of human gastric mucosae. We investigated whether the OMH4 extract could modify any protein of the preparations from human gastric mucosae. At first, homogenates of human gastric adenocarcinoma were assayed for mono-ADP-ribosylation in the absence or presence of OMH4 extract, and a representative result is shown in Fig. 2. When the cytosolic or membranous fraction of gastric carcinoma alone was incubated with [adenylate- ${ }^{32} \mathrm{P}$ ]-NAD, no protein gained endogenous radiolabeling in either fraction: furthermore, no endogenous 


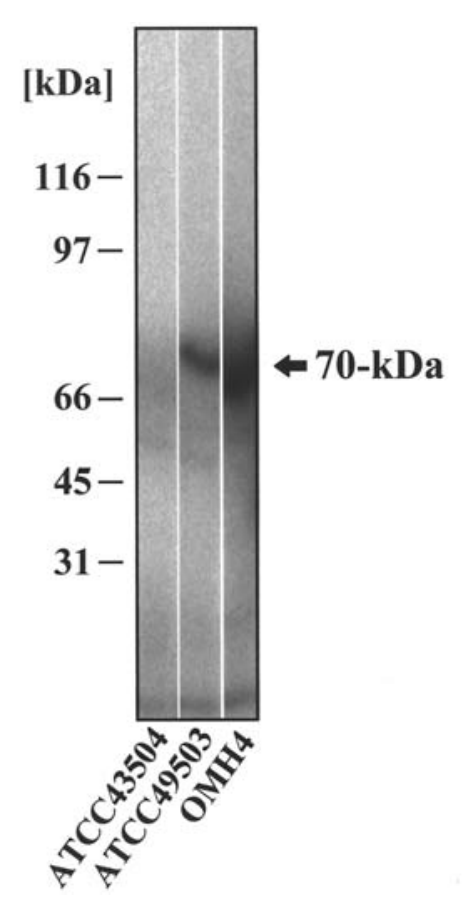

Figure 1. Incorporation of radioactivity in the extract of 3 different $H$. pylori strains. Thirty micrograms of $H$. pylori extract were subjected to a monoADP-ribosylation assay with [adenylate- $\left.{ }^{32} \mathrm{P}\right]-\mathrm{NAD}$. Samples were fractionated by $8 \%$ SDS-PAGE and analyzed by a subsequent radio-image analysis.

incorporation of radioactivity was found in the mixture of either fraction (Fig. 2, lanes 2-4). When the cytosolic fraction of gastric adenocarcinoma was assayed with OMH4 extract, no radiolabeling was newly induced other than that of $70-\mathrm{kDa}$ protein in the OMH4 extract (Fig. 2, lanes 5 and 6). In contrast, when the membranous fraction of gastric adenocarcinoma was assayed in the presence of OMH4 extract, 55- and 45-kDa proteins were newly radiolabeled, which were not observed without the OMH4 extract (Fig. 2, lanes 5 and 7). The induction of the 2 remarkable radiolabelings by OMH4 extract was observed in all 5 membranous fractions from gastric adenocarcinomas (shown as ' $\mathrm{C}$ ' in Fig. 3), but this reaction was not found in any cytosolic fraction from gastric adenocarcinoma when assayed with OMH4 extract (data not shown).

Similarly, when assayed with the OMH4 extract, only a slight degree of radioactivity was also incorporated into the $55-$ and $45-\mathrm{kDa}$ proteins in some of the membranous fractions of non-tumorous mucosae: however, the radiolabelings consistently tended to be minimal and much weaker than those of the respective gastric adenocarcinomas (shown as $\mathrm{N}$ in Fig. 3).

The radiorabelings of 70-, 55-, and 45-kDa proteins are caused by enzymatic mono-ADP-ribosylation. If NAD glycohydrolase activity existed in the OMH4 H. pylori extract, the $70-\mathrm{kDa}$ protein of $\mathrm{OMH} 4$ extract, or the $55-$ and $45-\mathrm{kDa}$ membranous proteins of human gastric mucosae might be modified nonenzymatically by free ADP-ribose generated, as previously reported (27). To rule out such a non-enzymatic NAD-dependent modification of proteins, excess cold NAD $(\leq 100 \mu \mathrm{M})$ or ADP-ribose $(\leq 1 \mathrm{mM})$ was added to the monoADP-ribosylation assay (20) using the membranous fraction

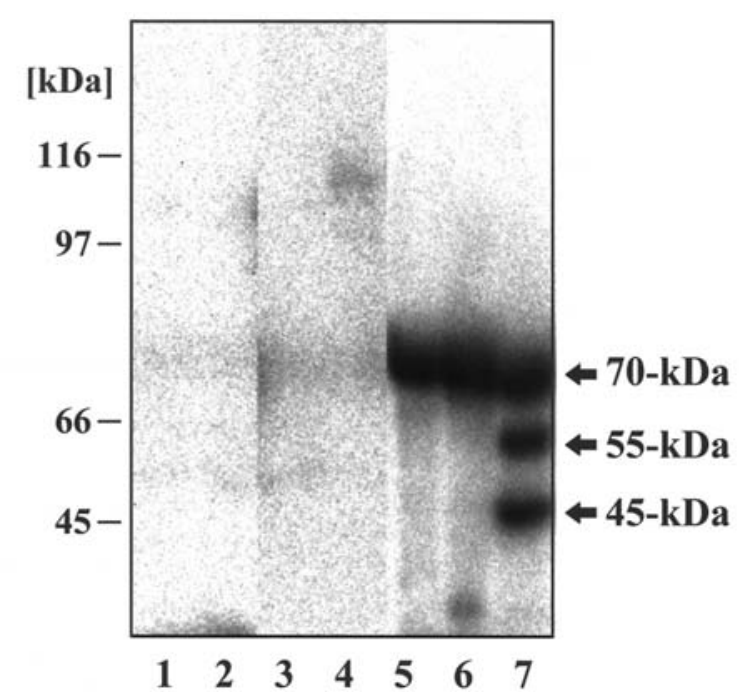

Figure 2. Profile of mono-ADP-ribosylation in cytosolic and membranous fractions from human gastric adenocarcinoma homogenates with or without H. pylori (OMH4) extract. All samples were subjected to a mono-ADPribosylation assay in the presence of $3 \mathrm{mM} 3$-aminobenzamide as an inhibitor of poly-ADP-ribosylation, and were analyzed by $8 \%$ SDS-PAGE and subsequent radio-image analysis. Lane 1, control medium; lane 2, cytosolic fraction of gastric adenocarcinoma; lane 3, membranous fraction of gastric adenocarcinoma; lane 4, mixture of cytosolic and membranous fractions; lane 5, OMH4 extract; lane 6, mixture of OMH4 extract and cytosolic fraction of gastric adenocarcinoma; lane 7, mixture of OMH4 extract and membranous fraction of gastric adenocarcinoma. The positions of the molecular mass standards $(\mathrm{kDa})$ are indicated. Similar results were obtained when samples from the other 4 patients were used.

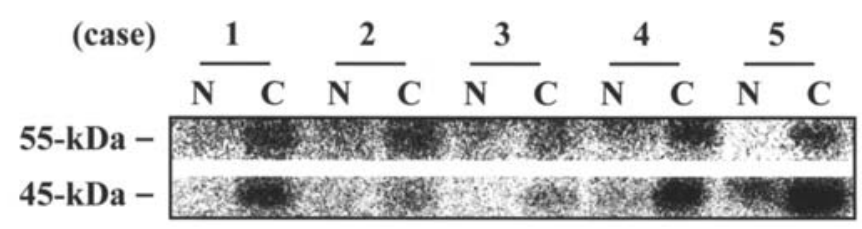

Figure 3. Mono-ADP-ribosylated levels of 55- and 45-kDa proteins in the membranous fractions of human gastric adenocarcinomas and adjacent nontumorous mucosae by $H$. pylori (OMH4) extract. Thirty micrograms of membranous fractions from human gastric adenocarcinoma and adjacent non-tumorous mucosa were subjected to the reaction in the presence of $30 \mu \mathrm{g}$ of OMH4 extract. Thereafter, the labeled proteins were analyzed by $8 \%$ SDS-PAGE and subsequent radio-image analysis. N, non-tumorous mucosa; $\mathrm{C}$, gastric adenocarcinoma tissue.

of gastric adenocarcinoma with OMH4 extract. Fig. 4 shows that unlabeled NAD blocked all the 3 radiolabelings of 70-, 55-, and 45-kDa proteins in a concentration-dependent manner, whereas, in contrast, the addition of cold ADP-ribose had no effect on the levels of radiolabelings. Similar results were obtained in the other cases.

To examine the temperature stability of this reaction, OMH4 extract was heated for $3 \mathrm{~min}$ at $56^{\circ} \mathrm{C}$ and $95^{\circ} \mathrm{C}$, respectively (20). Thereafter, the membranous fraction of gastric adenocarcinoma was incubated with the heated OMH4 extract for mono-ADP-ribosylation. The preincubation of $\mathrm{OMH} 4$ extract at $56^{\circ} \mathrm{C}$ and $95^{\circ} \mathrm{C}$ largely decreased and completely inhibited, respectively, the reactions of all of the 3 radiolabelings of 70-, 55-, and 45-kDa proteins found in any of the 5 cases (data not shown). 


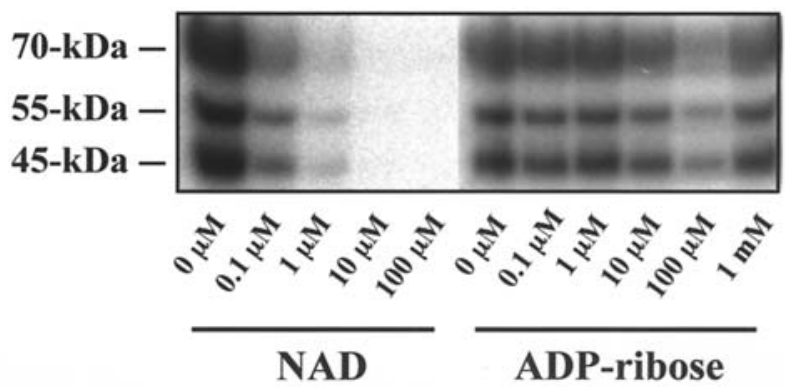

Figure 4. Influence of cold NAD and ADP-ribose on the radiolabeling of 70-, 55-, and 45-kDa proteins induced by H. pylori (OMH4) extract. MonoADP-ribosylation assays were performed in the mixture of membranous fraction from human gastric adenocarcinoma and OMH4 extract, under the presence of the indicated concentrations of unradiolabeled NAD or ADPribose. The radiolabeled proteins were analyzed by $8 \%$ SDS-PAGE and subsequent radio-image analysis. Data given are representative of the effects of cold NAD or ADP-ribose on the radiolabelings by mono-ADP-ribosylation of the membranous proteins from human gastric adenocarcinomas. $70-\mathrm{kDa}$, 70-kDa protein of OMH4; 55-kDa and 45-kDa, 55-kDa and 45-kDa proteins of human gastric adenocarcinoma, respectively.

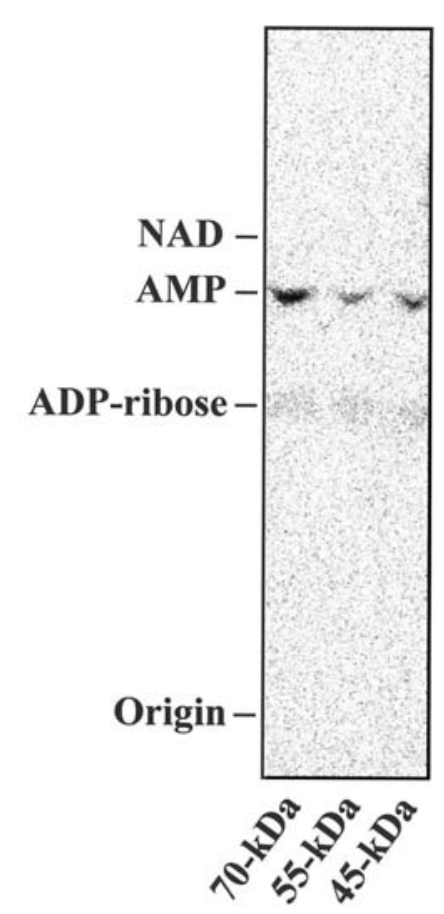

Figure 5. Products digested with snake venom phosphodiesterase from the radiolabeled proteins. After mono-ADP-ribosylation assay of the membranous fractions from human gastric adenocarcinoma with H. pylori (OMH4) extract, the radiolabeled proteins were separated by SDS-PAGE and transferred to a PVDF membrane, followed by radio-image analysis. Small pieces of the membrane carrying radiolabeled proteins were digested with snake venom phosphodiesterase, and the products were analyzed with thin-layer chromatography. Standard nucleotides were also developed on the same plate, and migrated at the positions indicated. $70-\mathrm{kDa}, 70-\mathrm{kDa}$ protein of OMH4; 55-kDa and 45-kDa, 55-kDa and 45-kDa proteins of human gastric adenocarcinoma, respectively.

Thymidine or 3-aminobenzamide, even at a low concentration, is known as an inhibitor of poly-ADP-ribosylation reaction $(25,26)$. However, the concentration of $3 \mathrm{mM}$ of 3 -aminobenzamide may have been too low to suppress polyADP-ribosylation, which may have thus contributed to the induced new radiolabelings. Therefore, the ADP-ribosylation

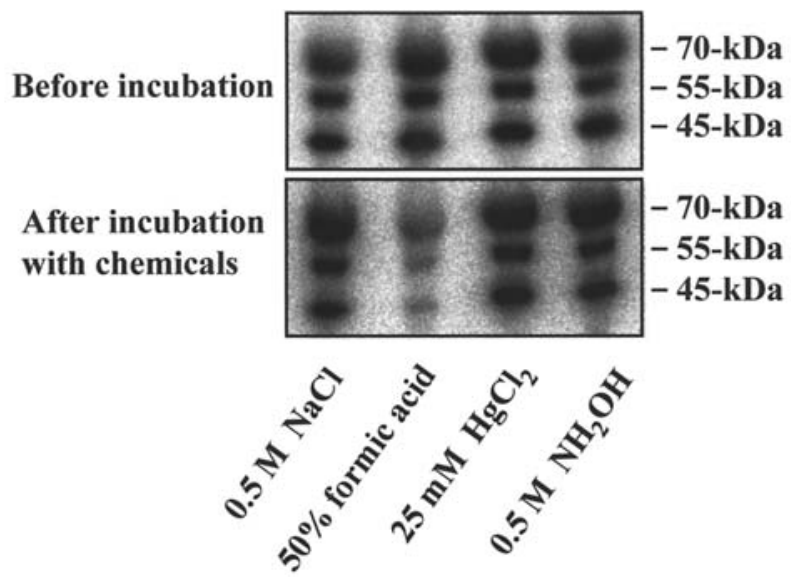

Figure 6. Chemical stability of ADP-ribose-protein bond. After mono-ADPribosylation assay of the membranous fractions from human gastric adenocarcinoma with $H$. pylori (OMH4) extract, the ADP-ribosylated proteins were separated by SDS-PAGE and transferred to a PVDF membrane, followed by radio-image analysis. The membrane was continuously incubated with $0.5 \mathrm{M} \mathrm{NaCl}, 50 \%$ formic acid, $25 \mathrm{mM} \mathrm{HgCl}_{2}$, or $0.5 \mathrm{M} \mathrm{NH}_{2} \mathrm{OH}(\mathrm{pH} 7.5)$ at $37^{\circ} \mathrm{C}$ for $3 \mathrm{~h}$, and subjected to a radio-image analysis for the second time. 70-kDa, 70-kDa protein of OMH4; 55-kDa and 45-kDa, 55-kDa and 45-kDa proteins of human gastric adenocarcinoma, respectively.

assay of the membranous fraction from gastric adenocarcinoma with $H$. pylori extract was performed under the presence of 3 -aminobenzamide at concentrations $\leq 10 \mathrm{mM}$. However, even the presence of $10 \mathrm{mM} 3$-aminobenzamide showed no effect on the levels of all of the 3 radiolabelings incorporated into 70-, 55-, and 45-kDa proteins in any of the 5 cases (data not shown).

For further substantiation of the result that the reactions were mono-ADP-ribosylation, we treated the radiolabeled proteins of OMH4 itself (70-kDa) and human gastric carcinoma (55- and $45-\mathrm{kDa}$ ) with snake venom phosphodiesterase, and thus analyzed the digested products by thin layer chromatography $(19,29)$. Then, all of the digested products from the modified 70-, 55-, and 45-kDa proteins proved to be AMP (Fig. 5).

Formic acid released radiolabels from 70-, 55- and 45-kDa proteins. Mono-ADP-ribosyltransferases transfer an ADPribose to specific amino acid residues: the various linkages can be discriminated on the basis of their different sensitivities to chemical treatments $(13,17,20,29,30)$. Incubation of the radiolabeled proteins of $H$. pylori itself $(70-\mathrm{kDa})$ and human gastric carcinoma (55- and 45-kDa) with $0.5 \mathrm{M} \mathrm{NaCl}, 25 \mathrm{mM}$ $\mathrm{HgCl}_{2}$, or $0.5 \mathrm{M} \mathrm{NH}_{2} \mathrm{OH}$ (pH 7.5) had no influence on the stability of radiolabelings. In contrast, treatment with $50 \%$ formic acid decreased the radiolabels from these 3 proteins in all 5 cases. A representative result is shown in Fig. 6. As a result, the ADP-ribose linkages in the 70-, 55-, and 45-kDa proteins proved to be labile in $50 \%$ formic acid, and these findings were consistent with the reported modification by $\mathrm{OMH} 4$ of serine, threonine, or tyrosine residues in the proteins $(20,29,30)$.

The radiolabeled proteins were neither G-proteins nor p53 protein. Some bacterial toxins are known to induce monoADP-ribosylation on G-proteins and to change their functions 
$(17,18)$. We therefore attempted to clarify whether the 3 radiolabeled proteins found in this study are somehow related to G-proteins, by an immunoprecipitation assay using antiGi $\alpha$ or anti-Gs $\alpha$ antibody. However, neither anti-Gi $\alpha$ nor anti-Gs $\alpha$ antibody precipitated any of the labeled 70-, 55-, and $45-\mathrm{kDa}$ proteins (data not shown). Therefore, the monoADP-ribosylated proteins found in this study were not $\mathrm{Gi}$ or Gs. Similarly, none of the mono-ADP-ribosylated proteins were identified as p53 by immunoprecipitation (data not shown).

\section{Discussion}

Mono-ADP-ribosylation is implicated in the regulation of a variety of biological reactions and a post-translational modification that modulates protein function $(13,16-22)$. The well-known mono-ADP-ribosyltransferases are several bacterial toxins (16-20). Recently, mono-ADP-ribosylation has been reported to be associated with a possible pathogenic factor of $H$. pylori (8). Namely, treatment of rat gastric epithelial cells with $H$. pylori VacA was found to reduce C. botulinum C3 exoenzyme-mediated ADP-ribosylation of Ras homologous (Rho) proteins, which may be related with inhibition by VacA of gastric ulcer re-epithelialization (8). However, to our knowledge, there has yet to be a report regarding mono-ADP-ribosylation of human gastric protein associated with $H$. pylori infection and gastric carcinogenesis.

In this study, there was no endogeneous mono-ADPribosylation induced in the human gastric protein of adenocarcinoma as well as adjacent non-carcinomatous mucosa, though some studies have described the presence of endogeneous mono-ADP-ribosylation in human tissue specimens $(13,17,31)$. In contrast, we demonstrated, for the first time, a strain-dependent, endogenous mono-ADP-ribosylation of $70-\mathrm{kDa}$ protein in the extract from $H$. pylori. The $H$. pylori extract prepared by our method contains the outer surface protein of itself, from which both of the transferase and the 70-kDa substrate may be derived. This endogenous monoADP-ribosylation of the $70-\mathrm{kDa}$ protein in the H. pylori extract is shared by at least 2 independent strains (OMH4 and ATCC49503). However, its level is very different and it is not observed in the other strain (ATCC43504), suggesting that either the mono-ADP-ribosyltransferase activity or the amount of $70-\mathrm{kDa}$ substrate for the transferase may depend on the $H$. pylori strain. In addition, our most significant finding in this study is that the extract from a clinical isolate of H. pylori, OMH4, can also induce exogenous mono-ADPribosylation in the $55-$ and $45-\mathrm{kDa}$ membranous proteins of human gastric mucosae in vitro: in particular, the radioactivities incorporated into those proteins by this modification are much greater in gastric adenocarcinomas than the respective non-tumorous mucosae. All three radiolabeling-reactions induced by the OMH4 extract were heat labile, and dependent on NAD but not on ADP-ribose, thereby ruling out the nonenzymatic modification by free ADP-ribose in the extract $(20,27)$. The observation that addition of 3 -aminobenzamide at $10 \mathrm{mM}$ had no effect on the levels of all of the incorporated radiolabelings excluded the existence of poly-ADP-ribosylation $(25,26)$. In addition, treatment with snake venom phosphodiesterase produced only AMP from any of the 3 radio- labeled proteins, consistent with findings indicating that the modification was mono-ADP-ribosylation $(19,29)$, since the phosphodiesterase treatment of poly-[ $\left.{ }^{32} \mathrm{P}\right] \mathrm{ADP}$-ribosylated protein must generate at least 3 radioactive products including AMP (12). We have confirmed that the OMH4-induced 3 radiolabelings of the 70-kDa protein of OMH4 itself (endogenous ribosylation) and the 55- and 45-kDa membranous proteins of human gastric mucosae, particularly adenocarcinomas (exogenous ribosylation), are not caused by non-enzymatic reactions or poly-ADP-ribosylation, but are instead produced by NAD-dependent enzymatic mono-ADP-ribosylation.

It is known that mono-ADP-ribosyltransferases transfer an ADP-ribose to specific amino acids in the target proteins $(13,17,20,29,30)$. For instance, cholera toxin transfers an ADP-ribose to an arginine residue of Gs, a GTP-binding regulatory protein of the adenylyl cyclase system $(17,18)$. However, since the identity of most of the endogenous ADPribose acceptor proteins is unknown, the ADP-ribosyltransferases have often been categorized according to their specificities for the amino acid modified $(20,30)$. According to the chemical stability of the ADP-ribose-protein bond, to speculate the amino acid residue to which ADP-ribose was bound, our results indicate that $\mathrm{OMH} 4$ may possess serine, threonine, or tyrosine-specific mono-ADP-ribosyltransferase activity $(20,29,30)$. The exact identification of the binding site for ADP-ribose, which is currently underway, will hopefully provide some useful explanations regarding the specificity or function of the enzymatic reaction. According to the findings of previous reports $(21,30,32,33)$, arginine-specific monoADP-ribosyltransferases were implicated in the regulation of adenylate cyclase activity via ADP-ribose modification of heterotrimeric $\mathrm{G}$ proteins as a membrane-associated process. In the present study, both the transferase and $70-\mathrm{kDa}$ substrate may be the surface proteins of $\mathrm{OMH} 4$, and the 55- and 45-kDa substrates for exogenous mono-ADP-ribosylation are only included in the membranous fraction of human gastric mucosae. However, the ADP-ribosylation we found is not argininespecific, and none of the mono-ADP-ribosylated proteins are G-protein, as well as p53 protein. The precise characterization followed by the identification of the acceptor proteins in the mono-ADP-ribosylation remains to be investigated to clarify their biological role in association with gastric cancer development.

In this study, the levels of the OMH4-induced monoADP-ribosylation in the 55- and 45-kDa proteins were much higher in all 5 adenocarcinomas than in the respective nontumorous mucosae. This in vitro observation could be explained by the supposition that, since all 5 patients in the present study were diagnosed to be $H$. pylori-infected before a gastrectomy, some ADP-riboses may thus have already bound to the acceptor proteins in normal gastric mucosae due to the $H$. pylori-induced mono-ADP-ribosylation in vivo. Thereafter, the mono-ADP-ribosylation may change the characterization and function of the proteins, as an initiator for gastric carcinogenesis. As previously indicated (4), H. pylori or its products may have a direct effect on the infected gastric cells by manipulating some cellular processes such as apoptosis or tumor suppression, playing a pivotal role in the early stage of gastric carcinogenesis. Another recent study also showed that no tumor-associated transcripts correlated with $H$. pylori 
infection (34), thus implying that the role $H$. pylori infection plays in gastric carcinogenesis precedes the development of overt cancers. These reports suggest the role of $H$. pylori infection as a tumor initiator, and they are also consistent with our hypothesis.

Alternatively, there is another supposition that the 55- and 45-kDa ADP-ribose acceptor proteins may be overexpressed more in gastric adenocarcinomas than in non-tumorous mucosae, while neither of the 2 proteins was determined by Coomassie brilliant blue staining in any sample (data not shown), to which the increased level of the OMH4-induced mono-ADP-ribosylation in gastric adenocarcinomas in vitro can be attributable. Because $H$. pylori cannot colonize effectively in gastric cancer (2), it remains unknown whether the distinct mono-ADP-ribosylation in gastric cancer found in vitro can be induced in vivo. However, it is possible that monoADP-ribosyltransferase could exist in the $H$. pylori-infected stomach as a product derived from the bacterium which still colonize in the adjacent normal mucosa, and that it may induce mono-ADP-ribosylation in the membranous proteins of cancer or preneoplastic lesions with which the products of $H$. pylori can directly come into contact. It is therefore also hypothesized that mono-ADP-ribosylation could play a role as a promotor in vivo in the regulation of growth and progression of gastric adenocarcinoma arising in the $H$. pylori-infected stomach. It is of interest and should be investigated how the identical proteins in preneoplastic lesions such as adenoma can be mono-ADP-ribosylated by the $H$. pylori extract. In addition, since bacterial pathogenic virulence depends on the strain (2), we hope to examine whether a clinical isolate of $H$. pylori from a gastric cancer patient can cause a similar mono-ADP-ribosylation in human stomach proteins.

H. pylori infection could have an indirect carcinogenic effect by triggering a strong inflammatory reaction followed by a cascade of molecular and morphological changes in the inflamed epithelium, atrophic mucosa or intestinal metaplasia, that are characteristic of the progression to intestinal-type gastric adenocarcinoma $(2,4,34)$. However, several statistical studies have shown that the status of $H$. pylori infection was not significantly associated with the histological type of gastric cancer $(2,3,6)$. In this study, all five patients were diagnosed with a $H$. pylori infection in their stomachs, and four of them had diffuse-type gastric cancer. Therefore, while the number of examined patients was small, the mono-ADP-ribosylation in the gastric mucosal proteins induced by $\mathrm{OMH} 4$ may be a potential mechanism which is involved in the development of diffuse-type gastric adenocarcinoma associated with $H$. pylori infection. However, since this reaction is one of the host responses to the infection, its level could vary depending on the H. pylori strain or the patient. Moreover, there must be multiple alternative mechanisms of tumor initiation and progression due to enormous heterogeneity of gene expression patterns in gastric carcinoma in comparison to other solid tumors (34).

In conclusion, this study has demonstrated, for the first time, that the extract of a clinical $H$. pylori isolate possesses mono-ADP-ribosyltransferase, which ADP-ribosylates not only endogenous proteins but also exogenous human gastric mucosal proteins in vitro, particularly in the membranous fraction of adenocarcinoma tissues. The possible scenarios based on our findings, which are not mutually exclusive, may contribute to the role that $H$. pylori plays in the development of human gastric adenocarcinoma. Further studies are underway to identify the 55- and 45-kDa mono-ADP-ribosyltransferase target proteins, and the possible pathophysiological roles and significance of this modification by $H$. pylori has yet to be elucidated from the viewpoint of an initiator or promoter of human gastric cancer.

\section{Acknowledgements}

The authors are grateful to Dr M. Miyake (Research Institute for Microbial Diseases, Osaka University), Professor F. Nomura and Dr T. Tomonaga (Department of Molecular Diagnosis, Chiba University Graduate School of Medicine) for their expert technical assistance and helpful discussion. We also thank Professor T. Fujioka (Department of General Medicine, Oita University Faculty of Medicine) for providing the OMH4 H. pylori strain. This work was partly supported by the Nakamura Memorial Fund from Chiba University School of Medicine, Japan (to Y. Nabeya).

\section{References}

1. Marshall BJ and Warren JR: Unidentified curved bacilli in the stomach of patients with gastritis and peptic ulceration. Lancet 1: $1311-1315,1984$

2. Huang JQ, Sridhar S, Chen Y and Hunt RH: Meta-analysis of the relationship between Helicobacter pylori seropositivity and gastric cancer. Gastroenterology 114: 1169-1179, 1998.

3. Parsonnet J, Friedman GD, Vandersteen DP, Chang Y, Vogelman JH, Orentreich N and Sibley RK: Helicobacter pylori infection and the risk of gastric carcinoma. N Engl J Med 325: 1127-1131, 1991 .

4. Mueller A, Falkow S and Amieva MR: Helicobacter pylori and gastric cancer: what can be learned by studying the response of gastric epithelial cells to the infection? Cancer Epidemiol Biomarkers Prev 14: 1859-1864, 2005.

5. Dubois A: Spiral bacteria in the human stomach: the gastric helicobacters. Emerg Infect Dis 1: 79-85, 1995.

6. Logan RP: Helicobacter pylori and gastric cancer. Lancet 344 : 1078-1079, 1994.

7. Cover TL: The vacuolating cytotoxin of Helicobacter pylori. Mol Microbiol 20: 241-246, 1996.

8. Pai R, Sasaki E and Tarnawski AS: Helicobacter pylori vacuolating cytotoxin (VacA) alters cytoskeleton-associated proteins and interferes with re-epithelialization of wounded gastric epithelial monolayers. Cell Biol Int 24: 291-301, 2000.

9. Higashi H, Tsutsumi R, Muto S, Sugiyama T, Azuma T, Asaka M and Hatakeyama M: SHP-2 tyrosine phosphatase as an intracellular target of Helicobacter pylori CagA protein. Science 295: 683-686, 2002.

10. Yahiro K, Wada A, Nakayama M, Kimura T, Ogushi K, Niidome T, Aoyagi H, Yoshino K, Yonezawa K, Moss J and Hirayama T: Protein-tyrosine phosphatase alpha, RPTP alpha, is a Helicobacter pylori VacA receptor. J Biol Chem 278: 19183-19189, 2003.

11. Fujikawa A, Shirasaka D, Yamamoto S, Ota H, Yahiro K, Fukada M, Shintani T, Wada A, Aoyama N, Hirayama T, Fukamachi $\mathrm{H}$ and Noda M: Mice deficient in protein tyrosine phosphatase receptor type $\mathrm{Z}$ are resistant to gastric ulcer induction by VacA of Helicobacter pylori. Nat Genet 33: 375-381, 2003.

12. Ueda K and Hayaishi O: ADP-ribosylation. Annu Rev Biochem 54: 73-100, 1985.

13. Koch-Nolte F and Haag F: Mono(ADP-ribosyl)transferase and related enzymes in animal tissues. In: ADP-Ribosylation in Animal Tissue. Haag F and Koch-Nolte F (eds). Plenum Press, New York, pp1-13, 1997.

14. Boulikas T: Relation between carcinogenesis, chromatin structure and poly(ADP-ribosylation). Anticancer Res 11: 489-527, 1991. 
15. Nomura F, Yaguchi M, Togawa A, Miyazaki M, Isobe K, Miyake M, Noda M and Nakai T: Enhancement of polyadenosine diphosphate-ribosylation in human hepatocellular carcinoma. J Gastroenterol Hepatol 15: 529-535, 2000.

16. Aktories K, Barmann M, Ohishi I, Tsuyama S, Jakobs KH and Habermann E: Botulinum C2 toxin ADP-ribosylates actin. Nature 322: 390-392, 1986.

17. Corda D and Di Girolamo M: Functional aspects of protein mono-ADP-ribosylation. EMBO J 22: 1953-1958, 2003.

18. Pallen MJ, Lam AC, Loman NJ and McBride A: An abundance of bacterial ADP-ribosyltransferases - implications for the origin of exotoxins and their human homologues. Trends Microbiol 9: 302-308, 2001.

19. Tao Y, Howlett A and Klein C: Nitric oxide stimulates the ADP-ribosylation of a 41-kDa cytosolic protein in Dictyostelium discoideum. Proc Natl Acad Sci USA 89: 5902-5906, 1992.

20. Geipel U, Just I and Aktories K: ADP-ribosylation of an approximately 70-kilodalton protein of Klebsiella pneumoniae. Infect Immun 64: 1720-1723, 1996.

21. Nomura F and Noda M: Stimulation of mono-ADP-ribosylation in rat liver plasma membranes after long-term alcohol intake. Hepatology 18: 870-873, 1993.

22. Nomura F, Noda M, Miyake M and Nakai T: Long-term alcohol intake enhances ADP-ribosylation of the multifunctional enzyme, phosphoglucomutase, in rat liver. Hepatology 24: 1246-1249, 1996.

23. Lauren P: The two histological main types of gastric carcinoma: diffuse and so-called intestinal type carcinoma. An attempt at a histo-clinical classification. Acta Pathol Microbiol Scand 64: 31-49, 1965.

24. Graham DY, Klein PD, Evans DJ Jr, Evans DG, Alpert LC, Opekun AR and Boutton TW: Campylobacter pylori detected noninvasively by the ${ }^{13} \mathrm{C}$-urea breath test. Lancet 1 : 1174-1177, 1987.
25. Rankin PW, Jacobson EL, Benjamin RC, Moss J and Jacobson MK: Quantitative studies of inhibitors of ADP-ribosylation in vitro and in vivo. J Biol Chem 264: 4312-4317, 1989.

26. Banasik M, Komura H, Shimoyama M and Ueda K: Specific inhibitors of poly(ADP-ribose) synthetase and mono(ADPribosyl)transferase. J Biol Chem 267: 1569-1575, 1992.

27. McDonald LJ and Moss J: Enzymatic and non-enzymatic ADPribosylation of cysteine. Mol Cell Biochem 138: 221-226, 1994.

28. Laemmli UK: Cleavage of structural proteins during assembly of the head of bacteriophage T4. Nature 227: 680-685, 1970.

29. Han MK, Lee JY, Cho YS, Song YM, An NH, Kim HR and Kim UH: Regulation of $\mathrm{NAD}^{+}$glycohydrolase activity by NAD(+)-dependent auto-ADP-ribosylation. Biochem J 318: 903-908, 1996.

30. Cervantes-Laurean D, Loflin PT, Minter DE, Jacobson EL and Jacobson MK: Protein modification by ADP-ribose via acidlabile linkages. J Biol Chem 270: 7929-7936, 1995.

31. Paone G, Wada A, Stevens LA, Matin A, Hirayama T, Levine RL and Moss J: ADP ribosylation of human neutrophil peptide-1 regulates its biological properties. Proc Natl Acad Sci USA 99: 8231-8235, 2002

32. Obara S, Yamada K, Yoshimura Y and Shimoyama M: Evidence for the endogenous GTP-dependent ADP-ribosylation of the alpha-subunit of the stimulatory guanyl-nucleotidebinding protein concomitant with an increase in basal adenylyl cyclase activity in chicken spleen cell membrane. Eur J Biochem 200: 75-80, 1991.

33. Quist EE, Coyle DL, Vasan R, Satumtira N, Jacobson EL and Jacobson MK: Modification of cardiac membrane adenylate cyclase activity and Gs alpha by NAD and endogenous ADPribosyltransferase. J Mol Cell Cardiol 26: 251-260, 1994.

34. Chen X, Leung SY, Yuen ST, Chu KM, Ji J, Li R, Chan AS, Law S, Troyanskaya OG, Wong J, So S, Botstein D and Brown PO: Variation in gene expression patterns in human gastric cancers. Mol Biol Cell 14: 3208-3215, 2003. 